\title{
Erratum to: Development of a Reconfigurable and Miniaturized CPW Antenna for Selective and Wideband Communication
}

\author{
Narbada Prasad Gupta ${ }^{1} \cdot$ Mithilesh Kumar $^{2}$ • \\ Ranjan Maheshwari ${ }^{2}$
}

\section{Erratum to: Wireless Pers Commun DOI 10.1007/s11277-017-3942-8}

The original version of this article unfortunately contained a mistake. Ranjan Maheshwari was not listed among the authors. The correct information is given in this erratum.

The online version of the original article can be found under doi:10.1007/s11277-017-3942-8.

$\triangle$ Narbada Prasad Gupta ernarbada@gmail.com

Mithilesh Kumar mith_kr@yahoo.com

1 Department of Electronics and Communication Engineering, Ideal Institute of Technology, Ghaziabad, India

2 Department of Electronics Engineering, Rajasthan Technical University, Kota, India 